\begin{tabular}{|c|c|c|c|c|c|}
\hline Cuadernos I. Geográfica & 14 & $1-2$ & $99-120$ & Logroño & 1988 \\
\hline
\end{tabular}

\title{
ABANDONO AGROPASTORIL Y RECOLONIZACION VEGETAL: EL PAPEL DE LAS ESPECIES LEÑOSAS COMO INDICADORAS DEL ESTADIO DE REGENERACION VEGETAL Y DE LA EDAD DEL ABANDONO (HAUT COUSERANS-PIRINEO CENTRAL FRANCES)
}

\author{
Emma Pérez-Chacón Espino* \\ Jacques Vabre**
}

\begin{abstract}
RESUMEN
En muchas zonas de montaña se ha generalizado un abandono agropastoril, consecuencia del éxodo rural. Este abandono ha desencadenado procesos de recolonización vegetal que han supuesto la inutilización de áreas tradicionalmente pastoreadas y una cierta transformación de los paisajes rurales. Esta recolonización vegetal presenta modalidades y «velocidades» diversas. Se realiza una aproximación a la datación de los campos abandonados a partir del análisis de la progresión de las plantas leñosas, en tres solanas (Bethmale, Faup y Aulus) del Haut Couserans, sector del Pirineo central francés especialmente afectado por el éxodo rural. Los resultados muestran cómo la temporalidad del proceso de recolonización vegetal está sujeta a «inversiones», «bloqueos» $y$ «aceleraciones», vinculados a las características del medio y a la historia de la parcela.
\end{abstract}

\section{SUMMARY}

An agricultural and pastoral abandonment has become general in many mountaineous areas, as a consequence of the depopulation of the countryside. This abandonment has unchained processes of vegetable recolonization that has caused the disabling of traditionally pastured areas and the transformation of rural landscape. This vegetable recolonization presents diverse varieties and «speeds». The author comes to an approximation to the chronology of country abandonment, by the analysis of the progression woody plants in three suntrap (Bethmale, Faup y Aulus) in Haut Couserans (Central Pyrenees, France). The results show how the evolution of processes of vegetal recolonization is subject to «inversions», "blockades» and «accelerations», related to the environmental characteristics and the plots history.

* Dpto. de Geografía. Colegio Universitario de Las Palmas de G.C. Apartado Correos 550. 35016 Las Palmas de G.C.

** Chargé d'études. Bureau d'études ITER. 10 rue Amelie, 31000 Toulouse 
Después de la Segunda Guerra Mundial el éxodo rural se convirtió en un fenómeno generalizado en Europa, aunque ya se había iniciado anteriormente. En las áreas de montaña este proceso se hizo aún más evidente. Como consecuencia se produjo un progresivo abandono agropastoril que ha tenido, junto a un gran número de repercusiones sociales (FABRE, 1977; TOSCA, 1977; ABADIE, et al. 1980; BARRUE-PASTOR, 1980; TAILLEFER, 1981), una incidencia notable en la transformación de los paisajes (DOUGUEDROIT y DURBIANO, 1976; REY, 1977).

El sistema tradicional de explotación de la montaña pirenaica (CHEVALIER, 1980) se basaba en la máxima utilización de los recursos ofrecidos por ésta y, a su vez, se fundamentaba en la abundante mano de obra. Incluso se llegaron a producir momentos de «sobreexplotación» del medio, coincidiendo con los máximos demográficos (segunda mitad del siglo XIX). La abundancia de brazos permitía un cierto control de la dinámica natural de la vegetación y de algunos procesos de erosión. El medio natural se encontraba relativamente «domesticado», al menos hasta el umbral que permitía el desarrollo tecnológico del momento.

La ruptura de este sistema tradicional, consecuente al éxodo rural, supondrá el abandono de la montaña en muchos sentidos: los campos dejan de cultivarse, poco a poco se transforman en pastizales y finalmente, con el retroceso de la ganadería, se abandonan por completo. Los sistemas de drenaje e irrigación de las parcelas se van deteriorando lo que favorece la formación de zonas hidromorfas. Los muros de los bancales y los caminos se van destruyendo, lo que acelera un buen número de procesos erosivos. La vegetación natural, sobre todo en los sectores donde las condiciones son favorables, irá progresivamente recolonizando el terreno del que fue expulsada cuando esas tierras se roturaron.

En definitiva, comienzan a nacer unos paisajes, hoy todavía «jóvenes», que están dando a la montaña una nueva fisonomía, no siempre coincidente con la clímax anterior. Quizás uno de sus rasgos más característicos sea el aspecto de mosaico que ofrecen: cada parcela abandonada tiene un aspecto particular, fruto de la interacción entre naturaleza y sociedad. El erial se convierte en la manifestación ecológica del abandono social.

Nuestro trabajo se centra en una región del Pirineo central francés (Haut Couserans) donde el abandono agropastoril constituye un fenómeno muy arraigado (CARCENAC, 1978), sobre todo en las vertientes de solana que representaron el núcleo de esa actividad en el pasado. El estudio tiene como objetivo realizar una aproximación a la dinámica de recolonización vegetal, desde el punto de vista de su evolución temporal. Se trata de esbozar algunas claves que permitan evaluar la velocidad con la que esos medios se transforman y aproximarnos a la «edad» del abandono. Para ello se han utilizado como indicadores las especies leñosas por cuanto permiten una mejor datación a través de la dendrocronología, al tiempo que resultan muy significativas de los diferentes estadíos de recolonización vegetal.

\section{METODOLOGiA}

El análisis de estos procesos de recolonización vegetal constituye una de las claves para entender los paisajes actuales de las áreas abandonadas. Asimismo, el hecho de determinar su dinámica podría ayudar a definir las técnicas más adecuadas para recuperar estos espacios y dar una respuesta a la comunidad local que pretende explotarlos, ya 
que muchos sectores tradicionalmente pastoreados han quedado inutilizados ante la progresión de especies vegetales no palatales.

La dinámica vegetal generada a partir del abandono ha sido ya objeto de numerosos estudios (GUYOT, 1951; COVARELLI, 1976; LEPART y ESCARRE, 1983; PUERTO, 1986; LLORENTE y LUENGO, 1986; DIAZ y PECO, 1988), sobre todo en lo referente a los estadíos iniciales. Se han intentado definir las especies pioneras en los diferentes medios así como las complejas relaciones de competencia que se crean (COVARELLI, 1975; NEWELL y TRAMER, 1978; FALINSKI, 1980; PEREZ-CHACON y VABRE 1985).

Pero el abandono no sólo genera fenómenos de sucesión vegetal sino que también presentan una dimensión temporal. La datación de los campos abandonados, a pesar de algunos intentos realizados (GAUSSEN y DURRIEU, 1971; CENCI, 1976; KING, 1981; DE PABLO et al., 1982; PEREZ-CHACON y VABRE, 1987) aparece como un problema pendiente.

Nuestra hipótesis consiste en estimar que las especies leñosas recolonizadoras son indicadoras del estadío de recuperación vegetal y del tiempo de abandono transcurrido. La aproximación al fenómeno se ha realizado a 3 niveles: primero se ha considerado una sola leñosa (Corylus avellana) muy extendida en el medio estudiado; en una segunda fase a la totalidad de las leñosas y finalmente, se ha relacionado su evolución con la del medio en su conjunto.

Para establecer la estrategia de muestreo se partió de un análisis geosistémico previo (PEREZ-CHACON y VABRE, 1985) que permitió definir las unidades de paisaje del Haut Couserans. A partir de él se seleccionaron tres solanas (Bethmale, Faup y Aulus) que presentaban características ecológicas y grados de abandono agropastoril distintos. La elección de los puntos de muestreo se realizó a partir de las geofacies definidas y cartografiadas en el estudio geosistémico. Se consideraron 108 estaciones que se caracterizaron a partir de 28 variables ecológicas y zooantrópicas. Estas estaciones fueron reclasificadas a través de un análisis multifactorial de corrrespondencias (VABRE, 1986; PEREZ-CHACON y VABRE, 1986) que permitió establecer una tipología de eriales. Esta se resume en los siguientes estadíos, que representan fases determinantes en la evolución vegetal de la parcela abandonada: prado de siega, pastizal degradado, erial, breña y bosquete.

Del total de estaciones sólo se retomaron las que aparecían clasificadas en las tres últimas categorías (erial, breñal y bosquetes), por considerar que es a partir de ellas cuando las leñosas comienzan a ser significativas. Sobre esta parte de la muestra se correlacionaron las variables «tiempo de abandono», resumidas en las siguientes categorías: (1) De 0 a 5 años; (2) De 5 a 10; (3) de 10 a 20; (4) De 20 a 40 y (5) Superior a 40 años, y la variable «abundancia/dominancia» de las diversas leñosas, utilizando las clases sigui entes: (+) Presencia, (1) De 0 a 10\% de recubrimiento, (2) De 10 a 25\%, (3) De 25 a $50 \%$, (4) De 50 a $75 \%$ y (5) De 75 a $100 \%$.

Este último parámetro, como se desprende de estudios previos, sintetiza una buena parte de variables ecológicas aunque, como veremos, presenta algunas limitaciones. Otros factores también considerados fueron el número de ejemplares jóvenes de leñosas y la fisonomía característica de cada especie, pues no todas tienen la misma capacidad de recubrimiento vegetal.

Finalmente, la correlación entre el tiempo de abandono y el recubrimiento del conjunto de leñosas permitió establecer algunas consideraciones sobre la dimensión temporal del proceso de recolonización vegetal. 


\section{LA ZONA DE ESTUDIO. (Fig. 1)}

El Haut Couserans se localiza en el sector oriental de los Pirineos centrales franceses. Su medio natural está condicionado por los fuertes contrastes topográficos y geomorfológicos, ya que se encuentra en la zona de contacto entre el Pirineo axial y su cobertera norpirenaica. Desde el punto de vista climático puede considerarse una montaña húmeda, pues le afectan las perturbaciones oceánicas del Oeste y Noroeste. No obstante, el Macizo del Valier $(2.838 \mathrm{~m}$.) constituye una barrera climática que favorece los contrastes pluviométricos entre los diferentes valles, propiciando un efecto de fachada. Esta región también se ve afectada ocasionalmente por los vientos del Sur que producen un cierto aumento de las temperaturas, sobre todo en las vertientes de solana.

Junto a estos factores, la oposición entre umbría y solana, el gradiente altitudinal y las pendientes contrastadas, han determinado el uso tradicional de estos valles y la distribución de la vegetación. El esquema de su distribución espacial es el siguiente:

- La mayor parte de las explotaciones forestales se localizan en las vertientes de umbría.

- Los pastos de verano (estivos) se localizaban en las partes culminantes de las solanas y umbrías.

- Los prados de siega aparecían èn las zonas intermedias de las solanas y en las artigas de umbria; hoy constituyen uno de los sectores donde el abandono se hace más patente por la rápida recolonización vegetal de estas zonas.

- Los cultivos se localizaban fundamentalmente en los fondos de los valles y en los sectores inferiores de las solanas, en la actualidad la mayor parte se han transformado en prados de siega o simplemente se han abandonado por completo.

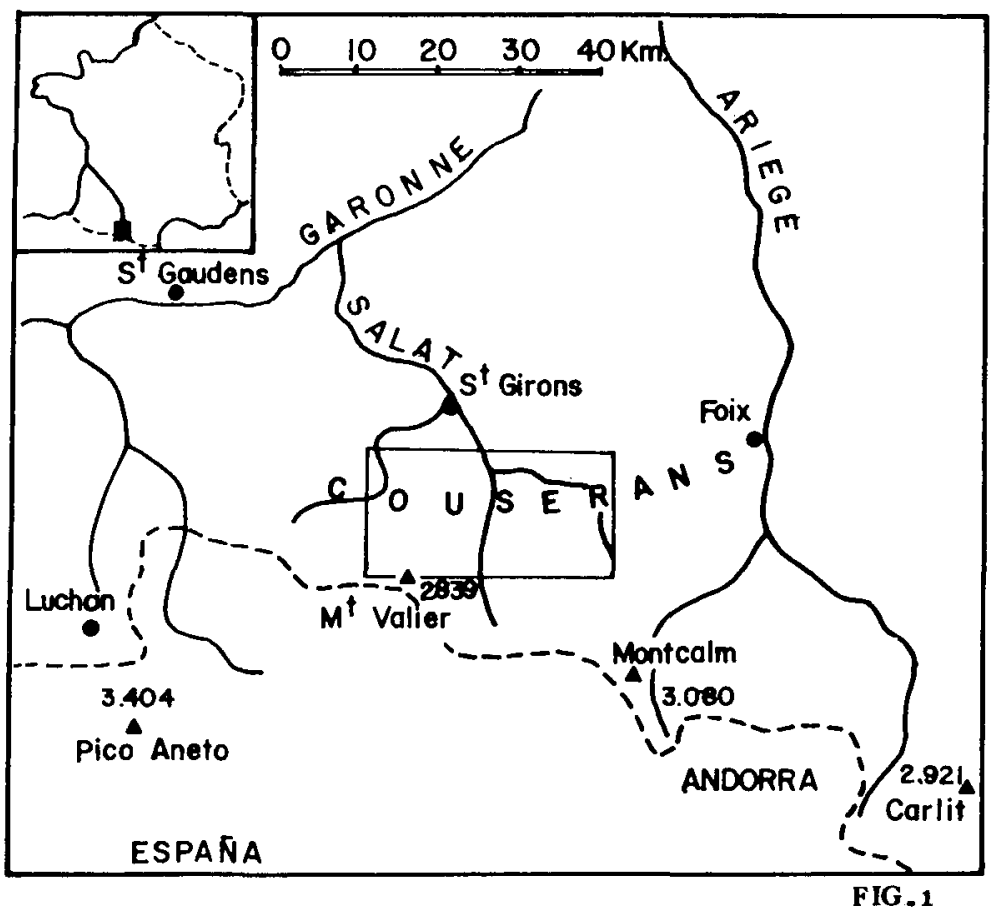


En este marco se inscriben los tres valles cuyas solanas hemos estudiado; sus principales características son las siguientes:

\section{a) Bethmale:}

Este valle, perteneciente a la cuenca de Castillon, posee unos $20 \mathrm{~km}^{2}$ y abarca altitudes que desde los $600 \mathrm{~m}$. superan $\operatorname{los} 2.000 \mathrm{~m}$. en las partes culminantes. Limita al NE con las cretas del Tuc de Pelates-Cap de Bouirex y al Sur con los macizos del Valier y Crabère. Existe una disimetría geológica entre la vertiente de solana y la de umbría: la solana está conformada por terrenos metamórficos (gneis) y la umbría por graníticos. En el contacto aparece una falla, cuya trayectoria sigue el curso del río.

La influencia de la erosión nival y fluvial caracteriza la parte superior del valle, mientras que la disección torrencial marca las amplias vertientes de la zona inferior, recubierta por depósitos coluviales.

La solana tiene una extensión de aproximadamente 1.000 ha. y su cota superior es de $1.870 \mathrm{~m}$. (Cap de Bouirex). Por su posición respecto al Valier y su orientación presenta un clima térmicamente más suave y ligeramente menos húmedo que el valle de Aulus. Las diferentes altitudes determinan un gradiente vertical de la vegetación que se traduce por una disimetría entre la parte alta y baja de la solana así como entre el sector Este y Oeste de la misma. Aparecen diferencias similares en la organización del espacio agropastoril. Se distinguen las siguientes unidades:

- Baja solana todavía en explotación.

- Solana media pastoral en vías de abandono.

- Solana media forestal.

- Solana alta con pastizales.

\section{b) Faup:}

Se sitúa entre el valle del Salat al Este y el valle de Estours al NO, limitando con el Valier. La solana presenta una superficie ligeramente superior a las 500 ha. y está comprendida entre los $600 \mathrm{~m}$. (Couflens) y los $1.934 \mathrm{~m}$. (Pic de Fonta) de altitud. Tiene una exposición dominante Sur, con algunos sectores al SE. El sustrato está formado por una alternancia de esquistos y calcoesquistos silúricos y devónicos que han sufrido un fuerte plegamiento.

El modelado fluvial ha diseccionado el conjunto de la vertiente y sólo en su parte superior se distinguen canales de avalanchas y pequeños neveros que denotan un proceso erosivo vinculado a la nieve. La altitud y la fuerte pendiente determinan también en esta solana un escalonamiento de la vegetación y un gradiente de abandono agropastoril. Se diferencian estas unidades:

- Baja solana muy abandonada (elevada recolonización vegetal) sobre sustrato esquistoso.

- Solana media pastoral, ligeramente utilizada, sobre sustrato calcoesquistoso.

- Solana forestal sobre sustrato calcoesquistoso.

- Solana alta con pastizales de verano. 


\section{c) Aulus:}

Este valle está limitado al Sur por el sector axial del Pirineo y al E y O por las cretas que dominan los valles de Massat y Ustou. Se extiende sobre casi $100 \mathrm{~km} .^{2}$, entre los $500 \mathrm{~m}$. y $2.500 \mathrm{~m}$. de altitud. Los sectores graníticos (Cominac, Ercé) ofrecen un modelado suave y describen pendientes moderadas. Estos contrastan con los afloramientos calizos que originan relieves vigorosos y describen acusadas pendientes. Las morfogénesis sucesivas han marcado profundamente el modelado de las vertientes: en la cuenca de recepción dominan las formas heredadas del glaciarismo cuaternario, mientras que en las partes bajas del valle la erosión fluvial recorta los depósitos morrénicos.

Tiene una pluviometría mucho más acusada que los valles de Bethmale y Faup, debido a su orientación, claramente expuesta a los vientos dominantes del Oeste. La solana presenta las siguientes subunidades de paisaje:

- Fondo de valle amplio (fluvio-glaciar) ocupado por prados de siega.

- Solana media pastoral sobre sustrato granítico o morrénico.

- Solana media pastoral sobre sustrato calizo o flysch.

- Alta solana forestal sobre sustrato granítico o morrénico.

- Alta solana forestal sobre sustrato calizo.

- Estivos pastorales sobre sustrato calizo.

- Estivos pastorales sobre sustrato esquistoso.

Las tres solanas representan estadíos de abandono agropastoril diferentes: en Aulus contrasta el sector inferior granítico, aún en explotación, con las zonas calizas donde el abandono es muy antiguo y los procesos de recolonización vegetal han sido muy intensos; Faup representa el estadío más acusado pero, a diferencia de la anterior, la baja solana es la que muestra las trazas de un mayor abandono; en Bethmale la baja solana continúa explotándose por una pequeña comunidad local y son las solanas medias y altas las que muestran una mayor reducción del espacio cultivado.

Así pues, se trata de tres solanas con características diferenciadas, tanto desde el punto de vista natural (sustrato, formas de modelado, suelos, exposición, altitud, vegetación...) como de su contexto socio-económico. Ello permite observar el proceso de recolonización en un medio, que si bien tiene un funcionamiento similar, ofrece una gama de matices lo suficientemente rica.

\section{EL AVELLANO (Corylus avellana): SU PAPEL COMO INDICADOR DEL ABANDONO AGROPASTORIL}

El avellano se usaba frecuentemente para delimitar los linderos de las parcelas cultivadas. Tras el abandono de estas actividades, esta especie comienza a recolonizar rápidamente el terreno. Por tanto, presenta un doble interés: aparece en un gran número de parcelas abandonadas y al mismo tiempo posee una gran capacidad de recolonización. Todo ello permite utilizar esta especie como indicadora del tiempo de abandono transcurrido, al menos en un cierto número de parcelas del área estudiada.

En una primera aproximación, hemos correlacionado el recubrimiento de esta especie (Abundancia-Dominancia) con el estadío de recolonización vegetal y con la edad del abandono. Asimismo, y con el fin de expresar indirectamente las características generales del medio, se han diferenciado las estaciones en función de las solanas en las que se localizan. 
Esta correlación se expresa en la figura 2. Si bien las tendencias no aparecen excesivamente marcadas, pueden señalarse algunas:

- Las parcelas que poseen avellanos relativamente jóvenes (edades inferiores a 10 años) y con un recubrimiento inferior al $25 \%$, se sitúan en el grupo «erial».

- En contraposición, las estaciones con avellanos de edades superiores a los 10 años y un recubrimiento de medio a importante, se encuentran en la categoría «bosquete».

- El grupo de «breñales», menos diferenciado, comprende avellanos con características intermedias: edades muy variables y recubrimientos comprendidos entre el 10 y el $25 \%$.

En general, la edad y la abundancia-dominancia del avellano permiten caracterizar el abandono. Esta especie leñosa puede ser considerada como un indicador del estado de recolonización vegetal. Da una idea del momento en el que la parcela ha comenzado a ser colonizada por los avellanos desde sus márgenes y, en consecuencia, supone un hito en el abandono de la misma. Así pues, puede afirmarse que las parcelas ocupadas por los avellanales más viejos y abundantes poseen un abandono superior a 20 años; por el contrario, cuando se trata de avellanos jóvenes y que recubren poco, nos encontramos ante un abandono inferior a 10 años.

\section{FIGURA 2}

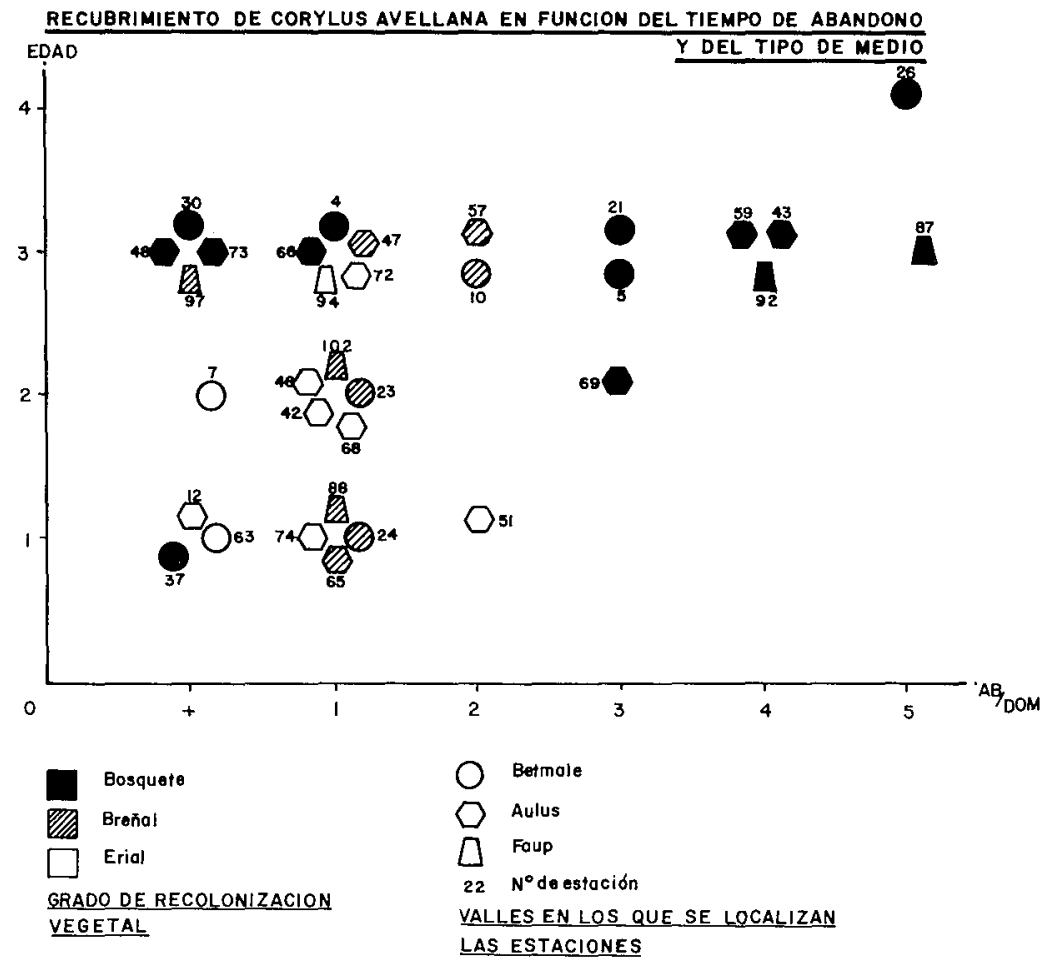

- Abundancia - dominancia (AB/DOM)

+ Presencia

1 Entre $0-10 \%$ de recubrimiento

2 Entre $10-25 \%$ de recubrimiento

3 Entre $25-50 \%$ de recubrimiento

4 Entre $50-75 \%$ de recubrimiento

- Tiempo de abandono (Edad)

1 De 0-5 años

2 De 5-10 años

3 De 10-20 años

4 De 20-40 años

5 Entre $75-100 \%$ de recubrimiento

5 Superior a 40 años 
Aunque evidentes, estas dos nociones deben ser matizadas. En ciertos casos hemos encontrado avellanos jóvenes, que recubren poco, y que aparecen incluidos en la categoría «bosquete». Por ejemplo, en la estación 37 esta especie ocupa estratos inferiores donde otras plantas, dadas las condiciones ecológicas, se encuentran mejor adaptadas para recolonizar el terreno. Por lo tanto, una sola especie aunque sea fuertemente indicadora, no basta para caracterizar la evolución y la edad de una parcela determinada. Es interesante, en una segunda aproximación, considerar el conjunto de las especies leñosas.

\section{CARACTERIZACION DEL ESTADO DE ABANDONO DE LA PARCELA EN FUNCION DE LA RECOLONIZACION DEL CONJUNTO DE ESPECIES LEÑOSAS}

Del total de estaciones muestreadas se han seleccionado algunas significativas que representan, en las tres solanas, diversos estadíos de recolonización vegetal (erial, breñal y bosquete). Estos estadíos de abandono se han correlacionado con la edad y el recubrimiento vegetal de las leñosas que aparecen con mayor frecuencia (Fig. 3 y 4). Para determinar si se encontraban en progresión o estabilizadas se ha considerado el número de ejemplares jóvenes que las acompañan.

Destaca la variedad de situaciones que se traduce por un paisaje en «mosaico», donde cada parcela muestra una fisionomía vegetal fruto de la interacción entre procesos naturales (condiciones ecológicas, capacidad colonizadora de cada especie, potencial de semillas próximo, etc...) y procesos zooantrópicos. Asimismo, se constatan determinados bloqueos: algunas parcelas abandonadas han quedado estancadas en fases de erial durante muchos años y no parecen evolucionar hacia estadíos de breñal o bosquete.

Destacamos algunos casos significativos del estadío de erial (Fig. 3): Las estaciones 42, 52, 74 corresponden a la solana de Aulus. En la 42 aparecen numerosas leñosas, relativamente viejas, pero que recubren poco. El erial parece «envejecer» pero no se transforma fisionómicamente. Se trata de una geofacies de escarpe calizo, donde las condiciones ecológicas limitan su desarrollo. El erial se encuentra, por el momento, estabilizado. La estación 52 representa un matorral bajo de Calluna vulgaris y Vaccinium myrtillus, muy extendido pero de corta edad. Esta parcela evoluciona hacia un matorral cuasi monoespecífico de Calluna vulgaris, donde otras leñosas no logran instalarse. Constituye pues otra forma de bloqueo, si ningún fuego pastoril perturba la situación (MET AILIE, 1981). En la estación 83 (Solana de Faup) se observa un proceso similar: el matorral joven de Calluna vulgaris y Vaccinium myrtillus progresa, la ausencia de otras leñosas es sintomática del bloqueo que se genera en este tipo de medios.

Como contrapunto a estas situaciones de estabilización de la vegetación, encontramos otras geofacies donde las condiciones ecológicas favorables permiten que los eriales se transformen rápidamente en breñal. Tal es el caso de la estación 74 , situada en la baja solana, sobre un sustrato morrénico y un suelo bien desarrollado, que han posibilitado la formación de un matorral mixto donde diversas leñosas ofrecen un recubrimiento y una edad media. 
Fig. 3.

CARACTERIZACION DE ALGUNAS ESTACIONES EN FUNCION DE LA EDAD DEL ABANDONO Y DE LA ABUNDANCIA-DOMINANCIA DEL CONJUNTO DE LENOSAS
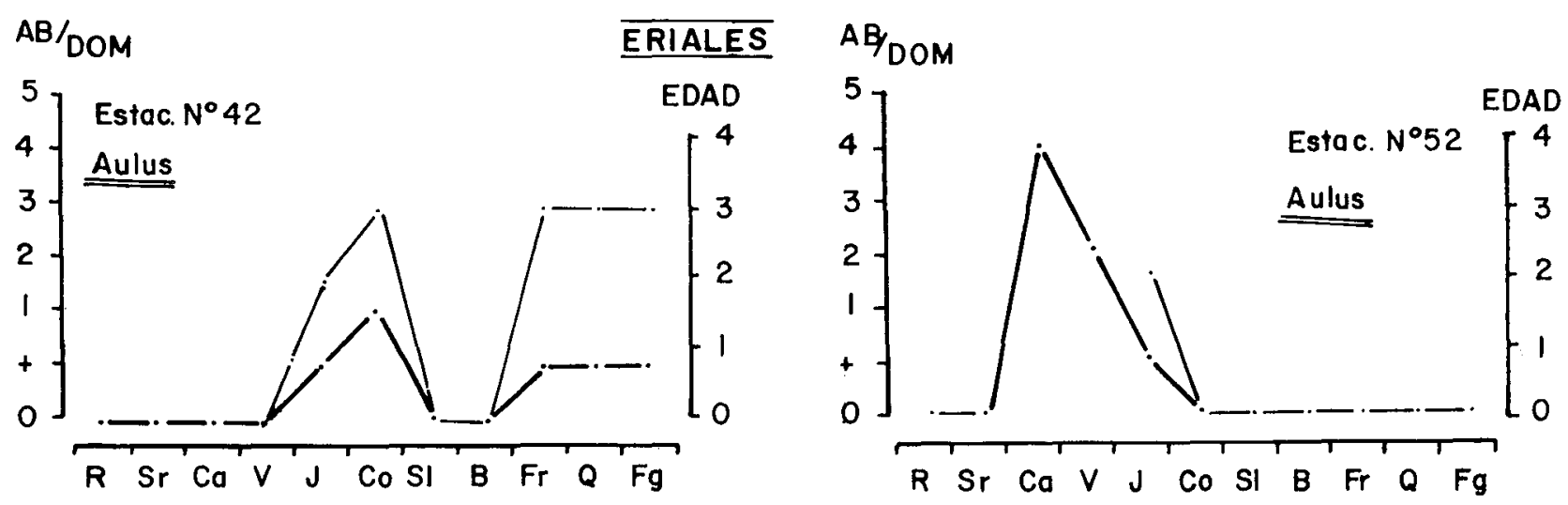

\section{AB DOM}
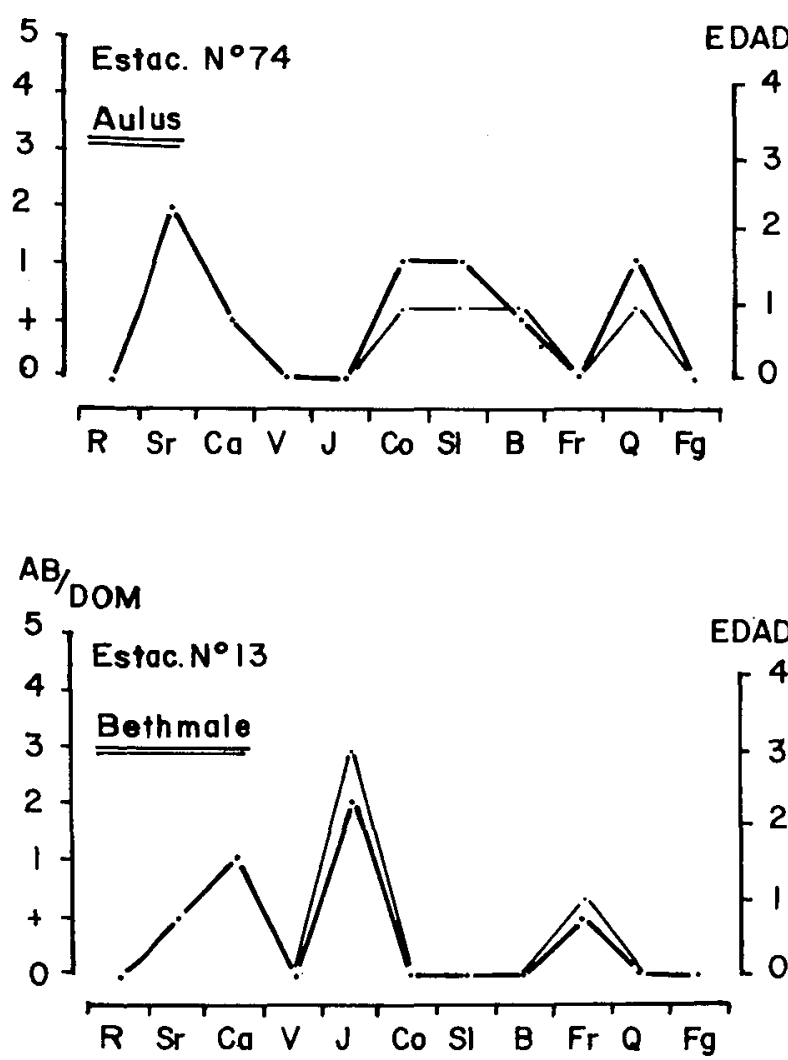

$$
\begin{aligned}
& R \text { - Rubus sp. } \\
& \text { Sr-Sarothamnus scoparius } \\
& \text { Ca-Calluna vulgaris } \\
& \mathrm{V} \text { - Vaccinium myrtillus } \\
& \mathrm{J} \text {-Juniperus communis } \\
& \text { Co-Corylus avellana }
\end{aligned}
$$$$
\text { -. }-A B / D O M
$$

\section{AB/DOM}
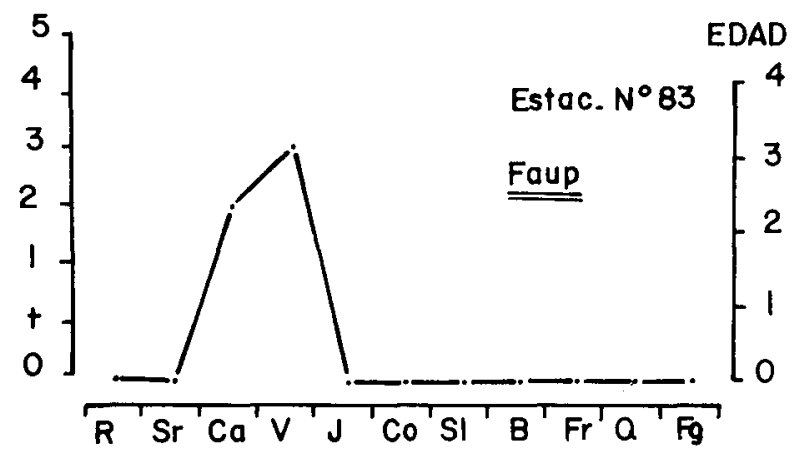

$A B$

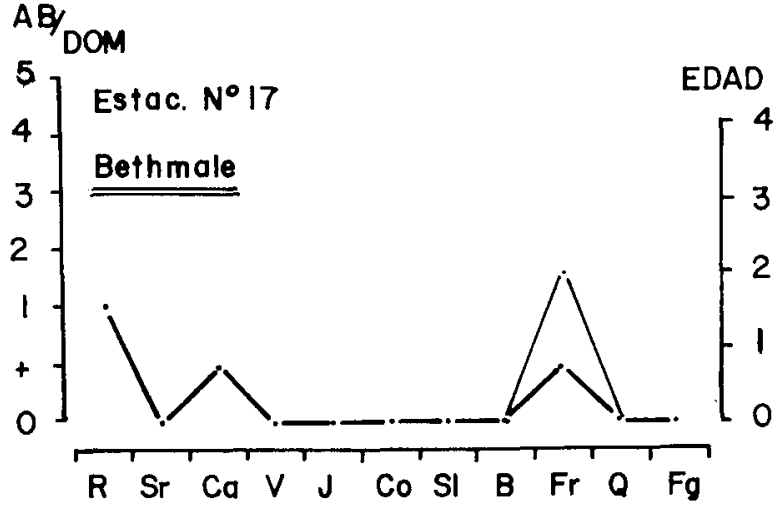

$$
\begin{aligned}
& \text { SI-Salix caprea } \\
& \text { B-Betula alba } \\
& \text { Fr-Fraxinus excelsior } \\
& \text { Q-Quercus sp. } \\
& \text { Fg-Fagus sylvatica }
\end{aligned}
$$


Fig. 4.

CARACTERIZACION DE ALGUNAS ESTACIONES EN FUNCION DE LA EDAD DEL ABANDONO Y DE LA ABUNDANCIA-DOMINANCIA DEL CONJUNTO DE LEÑOSAS
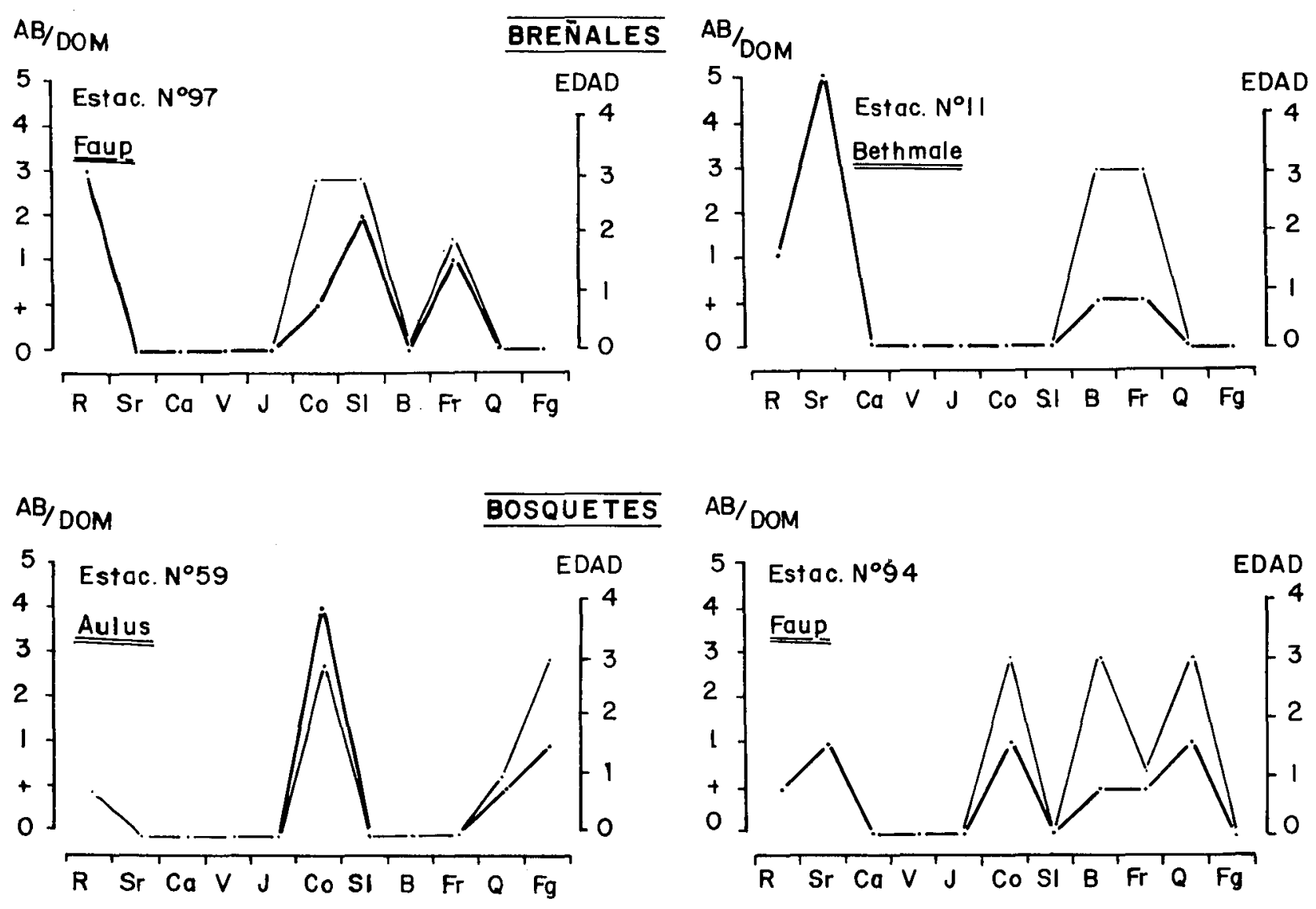

$A B / D O M$
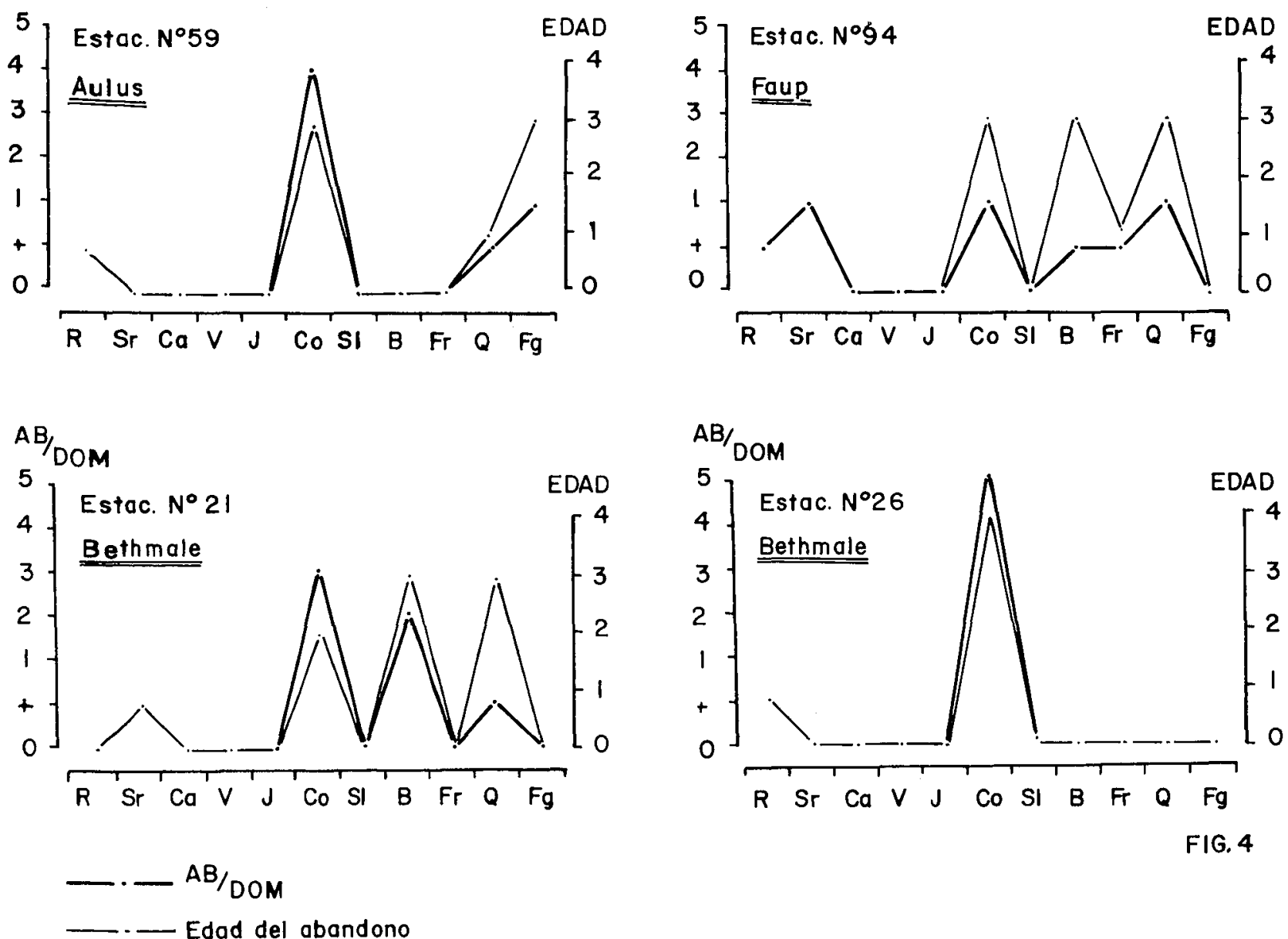

$A B / D O M$

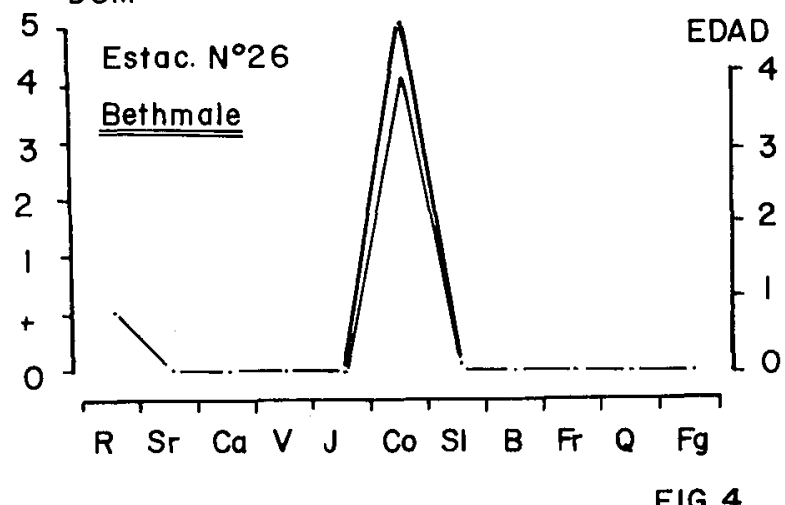

FIG. 4 
Las estaciones 13 y 17 (Solana de Bethmale) representan medios relativamente estabilizados. En la 13 se localiza un conjunto de Juniperus communis bastante viejo pero con un reducido recubrimiento. El matorral se cierra lentamente y el estadío de bosquete está lejos de alcanzarse. Tan sólo alguñas leñosas compiten por el espacio (Calluna vulgaris, Sarothamnus scoparius y Fraxinus excelsior), pero su recubrimiento no supera el 10\% de la parcela. En la 17 aparecen fresnos de edades comprendidas entre 5 y 10 años colonizando lentamente el terreno. Algunas leñosas jóvenes comienzan a extenderse.

Las estaciones 97 (Solana de Faup) y 11 (Solana de Bethmale) se corresponden con estadíos de recolonización vegetal más avanzados. La 97 pertenece a un medio muy húmedo caracterizado por el dominio de sauces y zarzas con edades comprendidas entre 10 y 20 años. También se localizan algunos jóvenes fresnos (entre 5 y 10 años) en franca progresión. La parcela evoluciona rápidamente a un breñal cerrado. En contraposición a esta dinámica vegetal más activa, la estación 11 refleja una geofacies que se ha estabilizado en el estadío de breña. Está ocupada por una comunidad de Sarothamnus scoparius que presenta un recubrimiento importante y edades que superan los 40 años. Sólo algunos jóvenes abedules y fresnos han logrado instalarse en ese largo intervalo temporal y se desarrollan con mucha dificultad.

En el estadío de bosquetes (Fig. 4) también se observan situaciones contrastadas. Parcelas con tiempos similares de abandono muestran grados muy diferentes de recubrimiento vegetal, sobre todo del estrato arbóreo. Es evidente que las condiciones del medio y la historia de la parcela, son nuevamente las responsables de estas disparidades.

Por ejemplo, en la estación 59 (Solana de Aulus) se localizan avellanos relativamente jóvenes (entre 10 y 20 años) que recubren ya el $75 \%$ de la parcela abandonada. Los robles y los fresnos, aunque presentes, no consiguen colonizar ese espacio. El dinamismo del avellano parece evidente.

La estación 26 (Solana de Bethmale) muestra un proceso similar, aunque denotando un estadío evolutivo más avanzado: un bosquete denso de avellanos, con edades próximas a los 40 años, recubre por completo la parcela abandonada. El medio se ha estabilizado y no aparecen ejemplares jóvenes de otras leñosas, sólo algunas zarzas se encuentran en las márgenes de la parcela.

En algunas ocasiones estos campos abandonados no evolucionan hacia formaciones relativamente monoespecíficas. Por ejemplo la estación 21 (Solana de Bethmale) se corresponde con una parcela donde la recolonización es compartida por Betula alba y Corylus avellana, de edades comprendidas entre los 10 y 20 años, y con númerosos ejemplares jóvenes de ambas especies. Sin embargo, los robles muestran dificultades para extenderse: aparece algún ejemplar viejo pero sin retoños que denoten su progresión.

Un ejemplo de recolonización diversificada, aunque ligeramente estabilizada, se constata en la estación 94 (Solana de Faup). La edad de los robles y avellanos (entre 10 y 20 años) contrasta con el escaso recubrimiento que poseen. Otras especies como Sarothamnus scoparius, Betula alba, Fraxinus excelsior, aunque presentes, también progresan lentamente.

En definitiva, el proceso de recolonización vegetal de una parcela abandonada en estas solanas presenta evoluciones diferenciadas: 
- cuando las condiciones ecológicas son favorables, estas parcelas se convierten, en intervalos temporales relativamente cortos, en breñales y bosquetes. Estos últimos a veces presentan un carácter monoespecífico, se establece una competencia interna entre las leñosas que suele culminar con el arraigo de las mejor adaptadas.

- sin embargo, en numerosas ocasiones se constata que esta evolución puede quedar bloqueada. El medio se estabiliza y permanece en estadíos de erial o breñal durante muchos años, sin pasar a configurar bosquetes o bosques.

Si bien la correlación entre la edad y la abundancia/dominancia del conjunto de leñosas parece significativa, resulta interesante en una tercera aproximación, situarla en su contexto ecológico y socio-económico. Conocer estos medios y la historia de la parcela, es otra forma de datar el momento inicial del proceso de abandono agropastoril.

\section{DE LA EDAD DE LAS LEÑOSAS A LA EDAD DE LOS MEDIOS: LOS ESTADIOS DE RECOLONIZACION VEGETAL}

La hipótesis de partida consiste en considerar la edad del árbol más viejo del medio estudiado -siempre y cuando no pertenezca al lindero o se encontrara anteriormente en la parcela- como la edad aproximada del comienzo del abandono.

Esta «datación» aproximativa corresponde, únicamente, al momento en el que las leñosas comienzan a colonizar la parcela. No siempre coincide con el abandono real (ausencia de siega regular, paso de un pastoreo intensivo a otro de carácter ocasional, etc...), ya que existe un lapsus de tiempo variable entre este tipo de abandono y la recolonización de las leñosas. Además esta hipótesis sólo es válida si no se considera la edad de los árboles vinculados al antiguo bocage. En la práctica son bastante fáciles de reconocer: toda ruptura en la diversidad de las edades y del porte, toda alineación próxima a los límites de la parcela, pueden ser considerados elementos fiables para diferenciar los árboles del bocage de los que han colonizado posteriormente la parcela abandonada.

Veamos en las tres solanas estudiadas la correlación entre el estadío de recolonización vegetal, la edad y las características del medio: (Fig. 5):

\section{- Solana de Bethmale (Fig. 5.a):}

No es necesario extenderse sobre la tendencia general reflejada en el gráfico de la Fig. 5.a: Cuanto más desarrollada está la vegetación, más antiguo es el abandono. Asimismo, se cumple la recíproca. Sin embargo, resulta más interesante constatar y explicar algunos casos «aberrantes», muchas veces más portadores de informaciones significativas.

Las estaciones 13 y 19 (parte superior del gráfico) tienen en común el hecho de estar situadas en la solana media superior (próxima a las crestas) y de presentar un mismo tipo de matorral, donde dominan Pteridium aquilinum, Calluna vulgaris, y Juniperus communis. Estos eriales, aunque antiguos, no evolucionan rápidamente al estadio de breñal o de bosquete. Los impedimentos ecológicos, pero sobre todo pastorales en este caso, explican el bloqueo. 
Fig. 5.
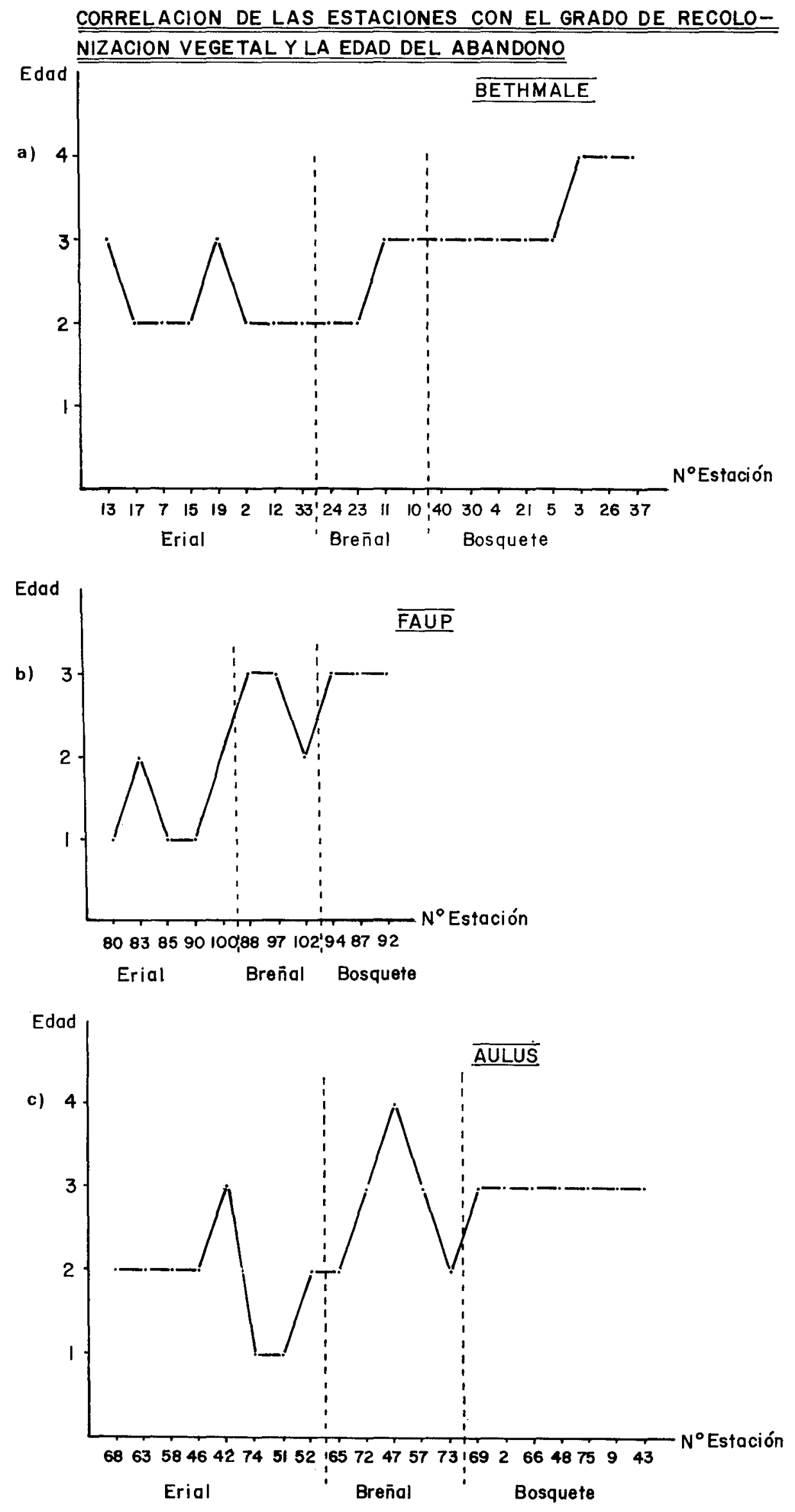
Las estaciones 23 y 24 representan el caso inverso: se trata de jóvenes breñas de Brachypodium pinnatum, zarzas y avellanos situados en la solana inferior, sector en el que la vegetación se desarrolla rápidamente tras el abandono completo.

- Solana de Faup (Fig. 5.b):

En esta solana la tendencia se verifica en todos los casos inventariados. Las estaciones 83 y 100, situadas en la solana media superior, presentan un matorral bajo con dominio de Calluna vulgaris que envejece sin evolucionar significativamente. El fuego pastoril mantiene estos eriales en unos estadíos, bien de pastizal degradado de Brachypodium pinnatum, bien en una landa de Calluna vulgaris.

En la solana media inferior (estaciones 94, 87 y 92) las condiciones ecológicas son mucho más favorables: estos bosquetes densos, de edades medias, se desarrollan y evolucionan rápidamente hacia formaciones vegetales progresivamente más cerradas.

\section{- Solana de Aulus (Fig. 5.c):}

Esta solana, como la de Bethmale, ofrece algunas «inversiones» en la evolución vegetal de sus campos abandonados. La estación 42 (ya descrita anteriormente) está ocupada por un erial de avellanos que se desarrollan con dificultad en la solana media superior (escarpes calizos). Los inconvenientes ecológicos no permiten que evolucione hacia un estadío de breñal o de bosquete.

Un hecho similar se observa en la estación 47: este breñal mixto de boj, avellanos, robles y enebros es antiguo, pero su fisionomía se mantiene bastante abierta. El soporte edáfico es un suelo poco desarrollado -rendzina- desfavorable al crecimiento vegetal. Además, es regularmente quemado (fuego pastoril). Este fuego, de carácter superficial, «limpia» el estrato herbáceo y subarbustivo sin afectar a los arbustos, ya antiguos y resistentes. Este medio es relativamente estable y su evolución se esquematiza en la Fig. 6. Constituye un buen ejemplo de la interacción entre procesos naturales y procesos antrópicos.

En Aulus, como en los valles citados anteriormente, la solana baja presenta unas condiciones mucho más favorables a la recolonización vegetal. Las estaciones 65 y 73 dan buena muestra de ello: la 65 es una breña de avellanos y robles con sotobosque de Brachypodium pinnatum; la 73 es otra breña colonizada por alisos, robles y sauces, con un sotobosque de Molinia caerulea. Ambas se localizan sobre suelos potentes desarrollados sobre una morrena. A pesar de su «corta edad» constituyen ya medios muy cerrados que evolucionan hacia bosquetes de robles y avellanos la primera, y de alisos y sauces la segunda.

Como muestra de la transformación del paisaje que puede generarse a partir del abandono agropastoril sugerimos la observación de las fotos 1 y 2 . Dan una idea de la rapidez con la que estos medios pueden evolucionar en algunos casos, así como de la estabilización que pueden presentar en otros. Ambas fotografías están tomadas sobre la solana de Aulus, pero las separa un intervalo de más de 50 años:

- las terrazas cultivadas o segadas localizadas sobre los depósitos morrénicos de la baja solana, se han transformado en breñales y bosquetes de avellanos y fresnos.

- la solana media, que en la foto antigua mostraba marcadas trazas de la erosión (abarrancamientos) debidas a la deforestación y al pastoreo intensivo, aparece hoy parcialmente recolonizada por un bojedal que ha atenuado considerablemente la erosión. 

sustancial.

- los escarpes calizos superiores son los que no han sufrido ninguna transformación

Finalmente, resumimos los datos aportados por las fichas de las estaciones de las tres solanas, considerando el número de parcelas que aparecen en cada estadío de recolonización vegetal y la edad que presentan:

- El estadío de erial muestra edades bastante variables, aunque nunca superan los 20 años. La clase 0 a 5 años es la que posee mayor número de efectivos.

- Los breñales se agrupan esencialmente en las clases de 5 a 10 años y de 10 a 20 años. Ninguna breña posee menos de 5 años.

- La mayoría de los bosquetes se sitúan en la categoría de 10-20 años, aunque existe un número significativo en la clase 20-40 años.

De esta forma nos acercamos a un esbozo de patrón, que aunque grosero, suponga una aproximación a la datación de los medios abandonados. No obstante, los procesos de recolonización vegetal tras el abandono agropastoril muestran una diversidad tal, fruto de la interacción entre el hombre y el medio, que estamos aún lejos de proponer un esquema generalizable. Por el momento, son muchas las dificultades para afinar esa secuencia temporal y sólo es posible destacar algunas tendencias generales.

Fíg. 6.

Interrupción del fuego
pastoril y del pastoreo

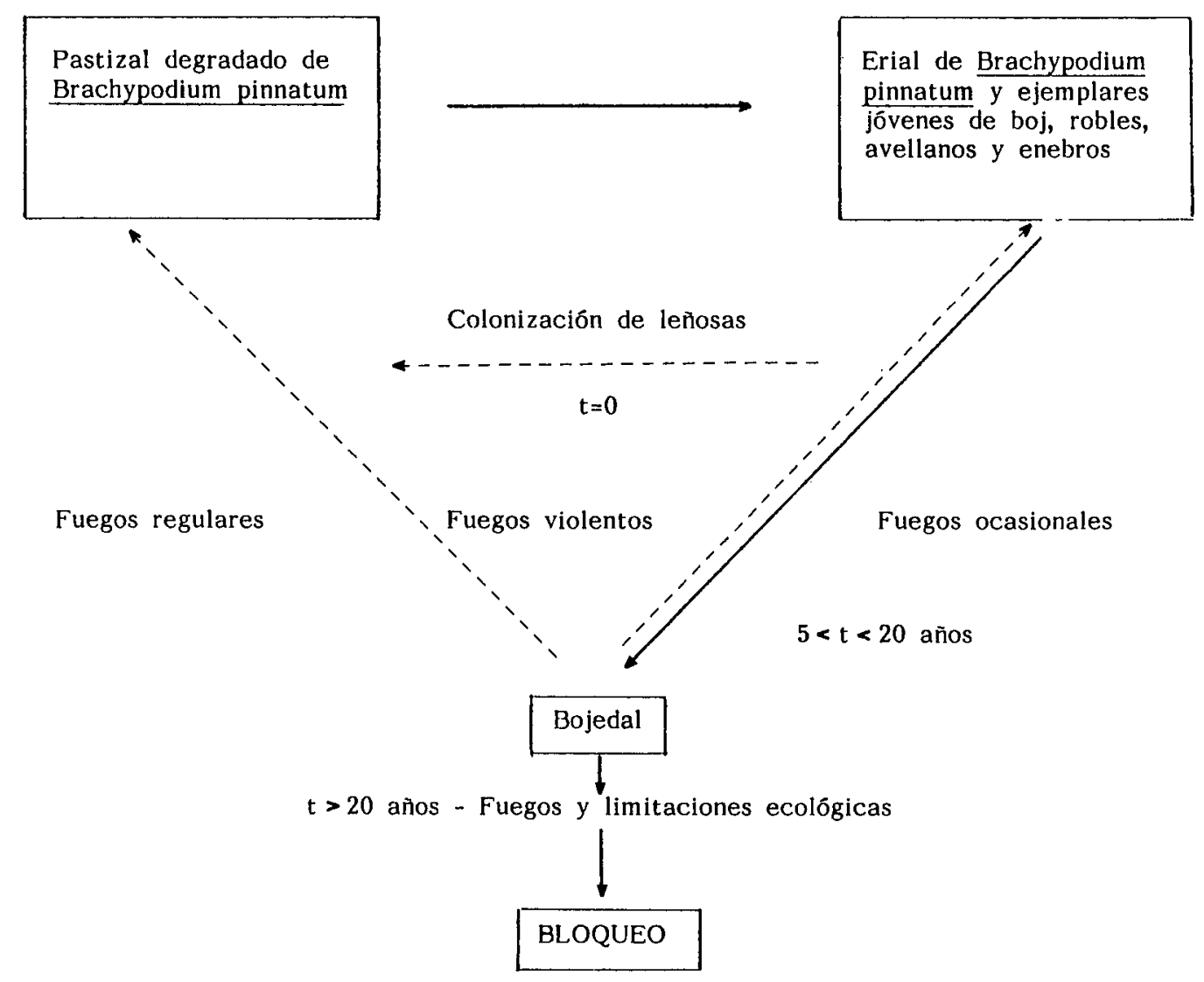

ESQUEMA DE LAS EVOLUCIONES POSIBLES DE UNA PARCELA ABANDONADA EN FUNCION DE LAS LIMITACIONES ECOLOGICAS Y DEL FUEGO PASTORIL. 
Como muestra de la especifidad de cada medio abandonado, a continuación mostramos un ejemplo en el que se observa claramente la interacción entre las actuaciones humanas y la dinámica natural: la recolonización vegetal de una vaguada granítica húmeda tras el abandono.

\section{UN MODELO DE RECOLONIZACION VEGETAL MUY CONDICIONADO POR FACTORES ECOLOGICOS Y ANTROPICOS: LAS VAGUADAS GRANITICAS HUMEDAS}

Las zonas «testigo» se han elegido en la solana inferior de Aulus, entre Ercé (615 m. de altitud) y Cominac ( $833 \mathrm{~m}$. de altitud).

El sustrato está formado por granodioritas erosionadas recubiertas en este sector por depósitos morrénicos. En los rellanos y vaguadas se han originado suelos arcilloarenosos, muy ácidos y poco drenados.

La explotación agropastoril de esta solana se ha llevado a cabo mediante importantes obras de adecuación del terreno: elaboración de bancales y realización de una infraestructura de canales que permitian el avenamiento y el riego de las parcelas.

El parcelario aparece muy fragmentado, como consecuencia del minifundismo tradicional de esta zona y de las características topográficas: abundancia de afloramientos rocosos, fuertes rupturas de pendiente, etc. La siega en estas condiciones resulta muy difícil. Así, la mayor parte de las zonas poco accesibles han sido progresivamente abandonadas, y el sistema de avenamiento colapsado. Como consecuencia de ello, muchas de estas vaguadas se han ido inundando y en ellas se ha generado un proceso de recolonización vegetal protagonizado por especies higrófilas. Se distinguen diversos estadíos en función del grado de abandono:

- Praderas húmedas aún en explotación.

Se sitúan, lógicamente, en las zonas más favorables, tanto desde el punto de vista de su accesibilidad como de sus condiciones ecológicas.

Presentan una composición florística ralativamente diversificada: dominio de leguminosas (Trifolium repens, Trifolium pratense, Anthyllis vulneraria, etc.) y de gramíneas (Festuca rubra, Holcus lanatus, Anthoxanthum odoratum, Poa pratensis, Briza media...) que comparten el territorio con otras especies características de estos prados: Euphrasia stricta, Brunella vulgaris, Ranunculus acris, Thymus serpyllum, Daucus carota, Rhinanthus minor, Plantago lanceolata, etc.

- Los primeros sintomas de degradación de los pastizales.

Estos síntomas se constatan cuando disminuye la presión pastoril sobre la parcela y la siega se realiza de forma irregular.

Los sectores menos húmedos, montículos o zonas con mayor pendiente, se degradan a partir de los linderos. Los setos vegetales, antes controlados por el ramoneo del ganado, comienzan a extenderse. También se aprecia un cierto deterioro de los canales de drenaje que comienzan a colmatarse y favorecen la extensión de las zonas encharcadas dentro de la parcela.

El pasto va empobreciéndose y algunas especies higrófilas comienzan a desarrollarse: algunas leguminosas (Anthyllis vulneraria, Trifolium repens) y gramíneas (Anthoxanthum odoratum, Holcus lanatus) disminuyen su presencia o desaparecen, dejando su lugar a especies hidrófilas como Molinia caerulea, Juncus conglomeratus, o Sphagnum sp. 
Otras plantas, presentes en el estadio anterior, también van progresivamente perdiendo efectivos, tal es el caso de Rhinanthus minor, Thymus serpyllum o de Euphrasia stricta.

-Del erial a la breña higrófila.

Cuando se degradan completamente los canales de drenaje, el proceso de recolonización vegetal se generaliza.

En los sectores algo más secos se desarrolla una breña compuesta por zarzas, helechos, avellanos y otras leñosas; en las zonas más húmedas se propaga el erial con dominio Molinia caerulea.

El agua va progresivamente encharcando el terreno, éste adopta poco a poco el aspecto de una turbera. El pastizal se va degradando y ya no resulta apetecible para el ganado, salvo en los períodos de menor pluviometría. En esos momentos constituye un complemento de hierba nada despreciable.

Se constata un empobrecimiento florístico y las especies características de estos pastizales son sustituidas por las higrófilas (Juncus conglomeratus, Spiraea Ulmaria, etc.). Las leguminosas desaparecen y las gramíneas sólo quedan representadas por dos o tres especies. Molinia caerulea ofrece en casi todos los casos un recubrimiento del $80 \%$ de la parcela.
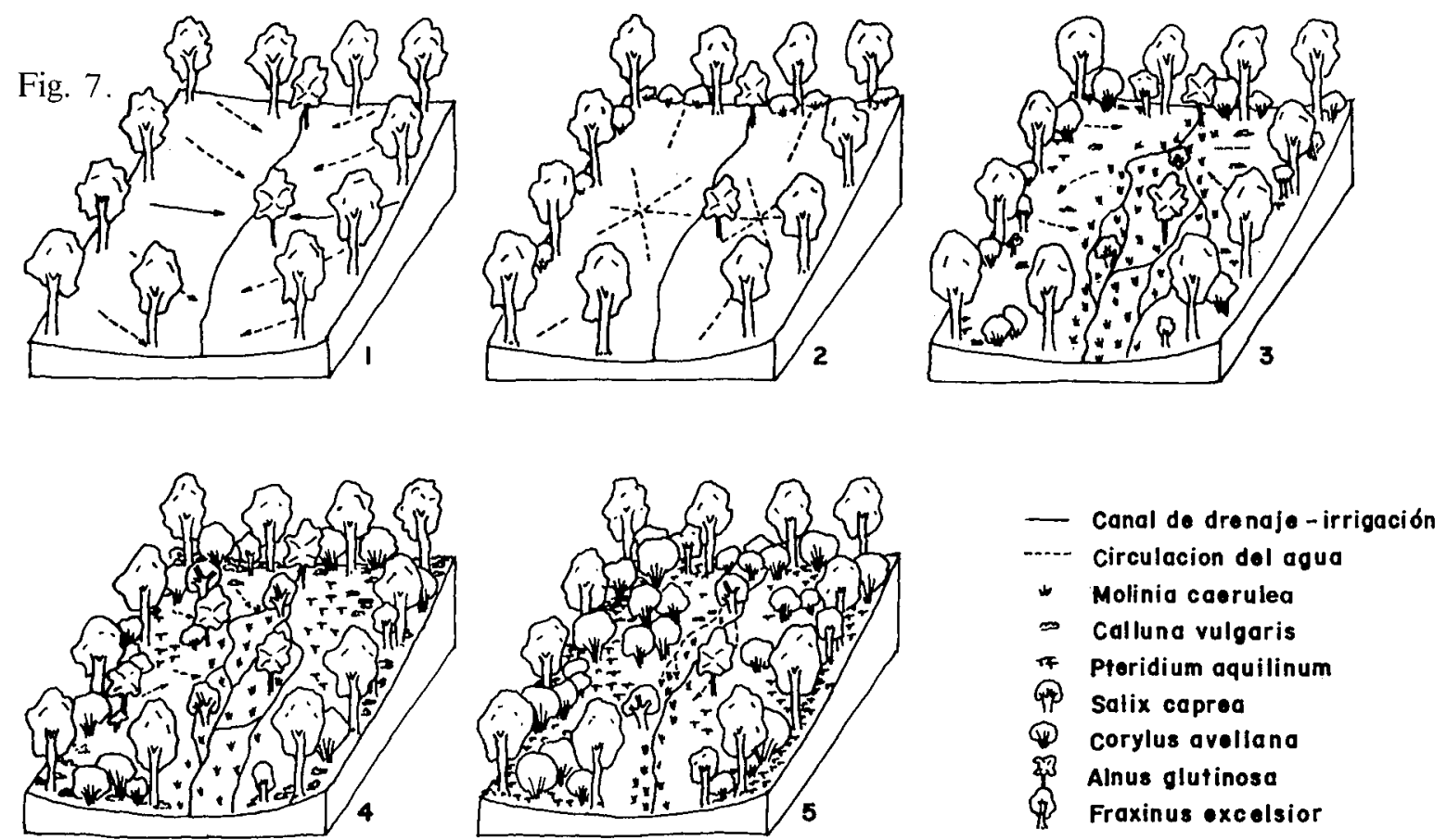

EVOLUCION DE UNA VAGUADA GRANITICA HUMEDA (Solana media inferior de AULUS-Pirineos Franceses)

1.- Prado de siega. Avenamiento bien conservado

2.- Degradación de los canales de drenaje. Pastizal mediocre

3.- Desorganización completo de la red de drenaje. Aparición de sp. higrófilas, progresión del avellano desde los linderos

4.- Colonización de Molinia caerulea, progresión de Sauces y Alisos. Ocupación de los linderos menos húmedos por leñosas

5.- Desecación relativa del medio. Desarrollo del conjunto de leñosas. Regresión de Sauces y Alisos, progresión de Avellanos y Robles 
En este estadío Molinia caerulea parece jugar un papel fundamental en la evolución de este tipo de eriales. Es capaz de competir eficazmente con el resto de las especies, e incluso con otras higrófilas: con su propia materia orgánica seca y sus raíces crea unos montículos que le permite aislarse ligeramente del agua y adquirir un mejor desarrollo por encima del agua estancada. Este proceso, también constatado por HEDIN et al. (1972), constituye una cierta forma de «autoconstrucción» de su propio nicho ecológico. Pero curiosamente, esta especie crea al mismo tiempo, las condiciones objetivas de su propia destrucción. En el estadío evolutivo posterior favorece la aparición de sectores desecados por ella misma, donde podrán instalarse especies menos higrófilas. Así esporádicamente, Calluna vulgaris o Rubus sp. comienzan a situarse sobre los montículos desecados. Con estas condiciones creadas, ya Salix caprea y Alnus glutinosa comienzan a instalarse en el erial, éste se transformará en una breña densa y finalmente, en bosquete, contribuyendo a un «secado» progresivo del terreno. Ante las nuevas condiciones creadas. Molinia caerulea irá desapareciendo.

- La consolidación del proceso: los estadios de breñal y bosquetes.

El abandono completo se traduce por la invasión generalizada de las leñosas y por una desecación relativa de la zona hidromorfa. Esta se explica por la propia dinámica interna de la vegetación: la instalación masiva de leñosas aumenta la biomasa y supone un mayor absorción de agua. En ocasiones hemos podido constatar como algunos factores exógenos pueden acelar la «desecación», por ejemplo la construcción de una pista forestal que facilita el desvío y la evacuación del agua que alimenta la zona hidromorfa.

Se produce entonces una dura competencia entre las especies colonizadoras. En un primer momento, Salix caprea domina sobre otras leñosas y Alnus glutinosa va debilitándose. En una segunda etapa, si perdura la progresiva desecación del medio, otras especies arbóreas de los linderos como Fraxinus excelsior y Corylus avellana irán paulatinamente ocupando la parcela, incluso algún roble logra instalarse. Asimismo, el sotobosque se transformará, desapareciendo las especies higrófilas.

De esta forma, si las condiciones topográficas son favorables, la antigua vaguada húmeda se transformará en un intervalo de algo más de 20 años, en un bosquete mixto de avellanos, fresnos y robles, con un sotobosque de Pteridium aquilinum, Deschampsia flexuosa, Fragaria vesca y, en algunos casos, Brachypodium sylvaticum.

La Fig. 7 da una imagen aproximativa de este proceso de recolonización vegetal en medios hidromorfos de solanas húmedas del Pirineo francés. Las condiciones ecológicas de estas solanas posibilitan que este proceso se desarrolle en un intervalo temporal relativamente corto. Se trata por tanto, de un medio con una capacidad de regeneración natural relativamente importante.

La datación de las parcelas abandonadas nos ha permitido elaborar el esquema de la Fig. 8. En él se correlacionan los diferentes estadíos de recolonización vegetal con el tiempo de abandono. La datación sólo es algo más precisa a partir de la aparición de especies leñosas, éstas constituyen la clave de nuestra datación (dendrocronología).

Este esquema, un tanto lineal, deberá se convenientemente matizado en función de las condiciones ecológicas y de las intervenciones antrópicas de cada medio particular. Pueden producirse bloqueos que impidan esta evolución y hagan que el proceso se estabilice en un estadío determinado. Por ejemplo, LLORENTE y LUENGO (1986) señalan, para el caso de algunos quiñones de los relieves paleozoicos del Oeste castellanoleonés, como las zonas hidromorfas pasan rápidamente a ser colonizadas por un brezal higrófilo (Erica tretralix, Genista falcata, Erica ciliaris y Genista anglica) que presenta un grado de persistencia muy grande y no evoluciona a estadíos más desarrollados. 
Fig. 8. EVOLUCION TEMPORAL DE LA RECOLONIZACION VEGETAL

DE UNA VAGUADA HUMEDA (Solana de Aulus-Pirineos).

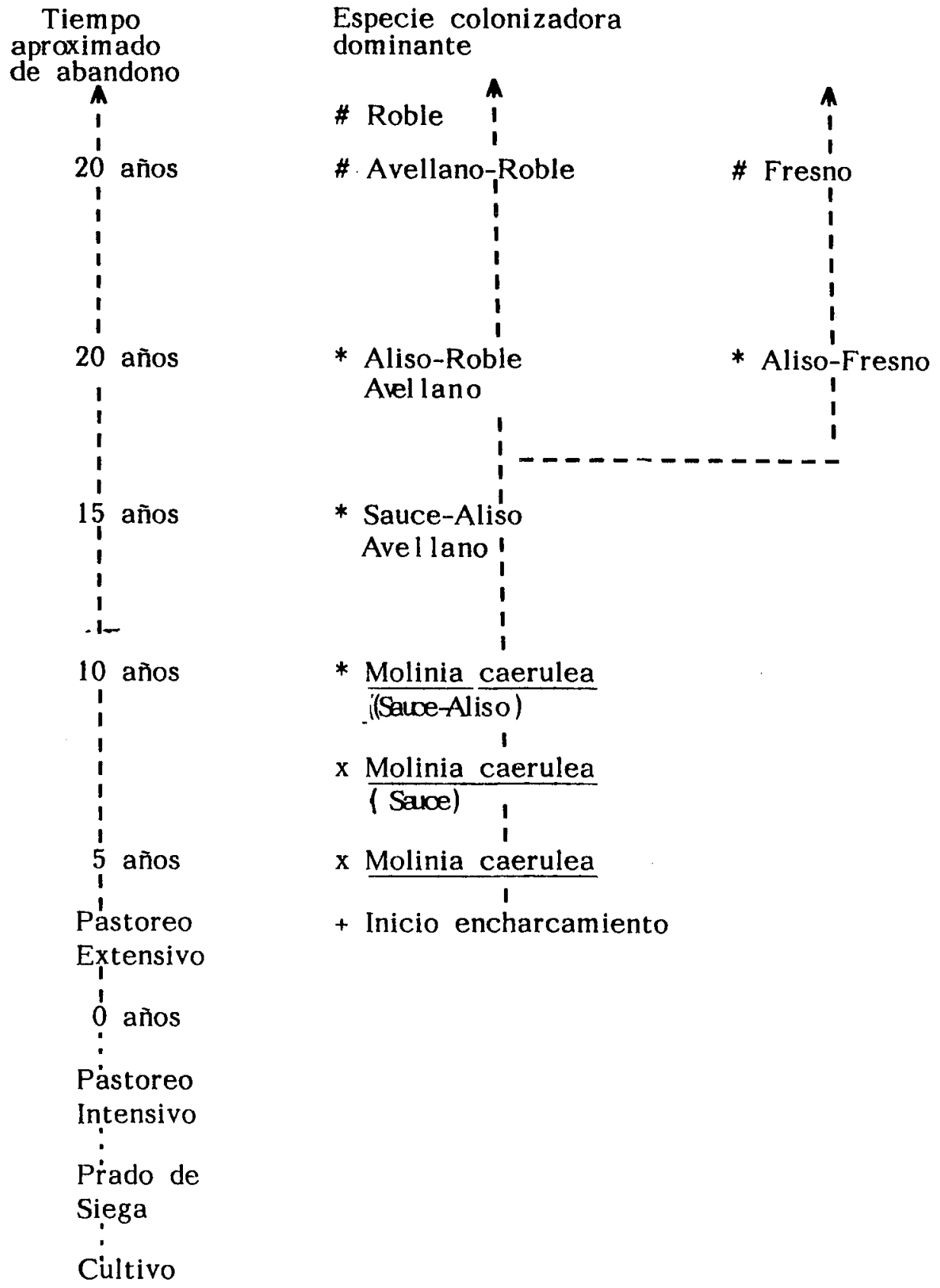
Símbolos utilizados: + Pastizal degradado $\mathrm{x}$ Erial
* Breñal \# Bosquete




\section{CONCLUSION}

El proceso de recolonización vegetal presenta una evolución compleja, ligada a fenómenos combinados y a veces contradictorios, fruto de la «herencia» ecológica y social. Ello supone que no es un proceso totalmente lineal, es decir, no siempre se evoluciona del estadío de pastizal degradado al de bosque «climático».

En las solanas estudiadas es significativo encontrar «inversiones» y «bloqueos» del proceso recolonizador: se constata que determinados eriales pueden ser mucho más antiguos que algunos bosquetes densos. El dinamismo del medio imprime, por tanto, distintas velocidades a la regeneración vegetal.

Cuando las condiciones ecológicas son favorables, los campos abandonados pueden transformarse, en intervalos temporales relativamente cortos (20 años) en breñales y bosquetes. En contrapartida, si existen factores limitantes las parcelas pueden permanecer un gran número de años en estadíos de erial. En los medios estudiados los eriales muestran edades bastante variables, aunque nunca superan los 20 años. Los breñales suelen presentar edades en torno a los 10 años y los bosquetes entre $\operatorname{los} 10$ y 20 años, aunque existe un grupo significativo en la categoría de 20 a 40 años.

Esta secuencia temporal no creemos que pueda generalizarse sino a otros medios de similares características. Trabajos actualmente en curso en áreas de montaña subtropical muestran una temporalidad muy diferente. Sin embargo el planteamiento del análisis quizás sea de mayor interés: las leñosas pueden ser utilizadas, correlacionando su edad y su recubrimiento vegetal, como indicadoras del tiempo de abandono de una parcela. Dan una idea del momento en el que ésta ha comenzado a ser colonizada por esas especies desde los linderos y, en consecuencia, supone un hito en el abandono de la misma. Esto deberá ser convenientemente matizado en cada caso en función de las características del entorno natural y social.

Las leñosas pueden ser uno de los «hilos de Ariadna» que, junto con otros métodos, permitan adentrarnos, en la datación de los campos abandonados.

\section{BIBLIOGRAFIA}

Abadie, P.; Chauvin, B.; Gabriel, J.M., 1980. La décomposition de la paysanerie montagnarde dans le canton de Luz-Saint Sauveur (Hautes Pyrénées). Géodoc, 15, Toulouse.

BARRUE-PASTOR, M., 1980. Utilisation du territoire, marché foncier et système social. Recherches sur l'élevage en Pyrénées, Compte rendu de recherches DGRST: 1-14.

CARCENAC, C., 1978. Les grandes unités éco-agrologiques des Pyrénées françaises. RGPSO, 49, (4): 443-454, Toulouse.

CENCI, C.A., 1976. Trials with Brachypodium pinnatum Beauv. pasture. Development of cover of the sward during five years. Rivista di Agronomia, 10, (1-2): 116-121, Penigia.

Chevalier, M., 1980. La vie humaine dans les Pyrénées ariégeoises. Ed. Résonances, 1060 pp., Paris. 
Covarelli, G., 1975. Richerche sulla competizione tra Brachypodium pinnatum Beauv. et alcune specie foraggere. Rivista di Agronomia, 9, (2-3): 246-251, Penigia.

Covarelli, G., 1976. Phytosociological study of vegetation on uncultivated hill land in Central Italy. Rivista di Agronomia, 10, (4): 249-260, Penigia.

De Pablo, C.T.; Peco, B.; Galiano, E.F.; Nicolas, J.P.; Pineda, F.D., 1982. Spacetime variability in mediterranean pastures analysed with diversity parameters. Vegetatio, 50: 113-125.

DíAZ, F.; PECO, B., 1988. Pastizales adehesados del área de El Pardo. Mundo cientifico, 8 (79): $386-395$.

Douguedroit, A.; Durbiano, C., 1976. Déclin de l'élevage et mutation des paysages dans le massif du Mont Ventoux. Actes Coll. Int. Inst. Rech. Med, Senanque.

FABRE, A., 1977. Quelques aspects de la déprise agricole en région de montagne. Application au Canton de Quérigut (Ariège). Bull. Ec., 8 (3): 237-242.

FALINSKI, J.B., 1980. Vegetation dynamics and sex structure of the populations of pionner dioecious moody plants. Vegetatio, 43: 23-38.

Gaussen, H.; Durrieu, G., 1971. Etude d'une prairie de montagne à 48 ans d'intervalle. Webbia, 25 (2): 465-479.

GUYOT, L., 1951. Sur un aspect du déterminisme biologique de l'évolution floristique de quelques groupements végétaux. Comptes rendus Som. Séances Soc. Biog., 239: 3-14.

Hedin, L.; Kerguelen, M.; Montard, F., 1972. Ecologie de la prairie permanente française. Ed. Mason, 229 pp., Paris.

KING, T.J., 1981. Ant-hills and grassland history. Journal of Biogeography, 329-334.

LEPART, J.; EsCARRE, J., 1983. La succession végétale, mécanismes et modèles: Analyse bibliographique. Bull. Ecol., 14: 133-178.

Llorente, J.M.; LUENGO, M.A., 1986. El abandono de las tierras: significado y gestión de las etapas de sucesión secundaria. El ejemplo de los relieves paleozoicos del W. Castellano-Leonés. Actas $V$ Reu. del G.T. de la U.G.I.: "Síntesis del paisaje»: 105-114, Banyoles.

Metallie, J.P., 1981. Le feu pastoral dans les Pyrénées Centrales. Ed. CNRS, 292 pp., Toulouse.

NeWELL, S.J.; TRAMER, E.J., 1978. Reproductive stratefief in herbaceous plant communities during succession. Rev. Ecology, 59 (2): 228-234.

PÉREZ-CHACón, E.; VABRE, J., 1985. Friches et enfrichements de la moyenne montagne ariégeoise (Pyrénées françaises). Une dynamique socio-écologique: l'exemple du brachypode (Brachypodium pinnatum P. Beauv.). Thèse $3^{\text {ème }}$ Cycle Geogra., 320 pp., Univ. Toulouse-Le Mirail.

PÉrez-CHACÓN, E.: VABRE, J., 1986. Cartografía y análisis multifactorial: métodos complementarios para el estudio de las alteraciones del paisaje a partir del abandono agrícola. Actas V Reu. del G.T. de la U.G.I.: «Síntesis del paisaje»: 189-198, Banyoles. 
Pérez-Chacón, E.; VABre, J., 1987. Cartographie de l'enfrichement: 1841-1985. L'exemple de la Soulane de Faup-Haut Couserans (Pyrénées françaises). Rev. Pirineos, 129: 59-78, Jaca.

Puerto, A., 1986. La sucesión ecológica: una aplicación generalizada para la zona de dehesas de la provincia de Salamanca. Rev. Prov. Est. Sal., 18-19: 431-450, Salamanca.

REY, P., 1977. Expression cartographique des modèles dynécologiques en région de montagne. Bull. Ec., 8.

TAIllefer, F., 1981. La moyenne montagne ariégoise malade de la dépopulation. Bull. Soc. Ariég. S.L.A., 217-223.

TosCA, C., 1977. Modalités et conséquences de la régression de l'agriculture dans la commune de Quérigut (Ariège). Bull. Ecol., 8 (3): 281-288.

VABRE, J., 1986. Le brachypode dans l'enfrichement des soulanes de l'Ariège (Haut Couserans-Pyrénées centrales). RGPSO, 57 (3): 325-341, Toulouse. 


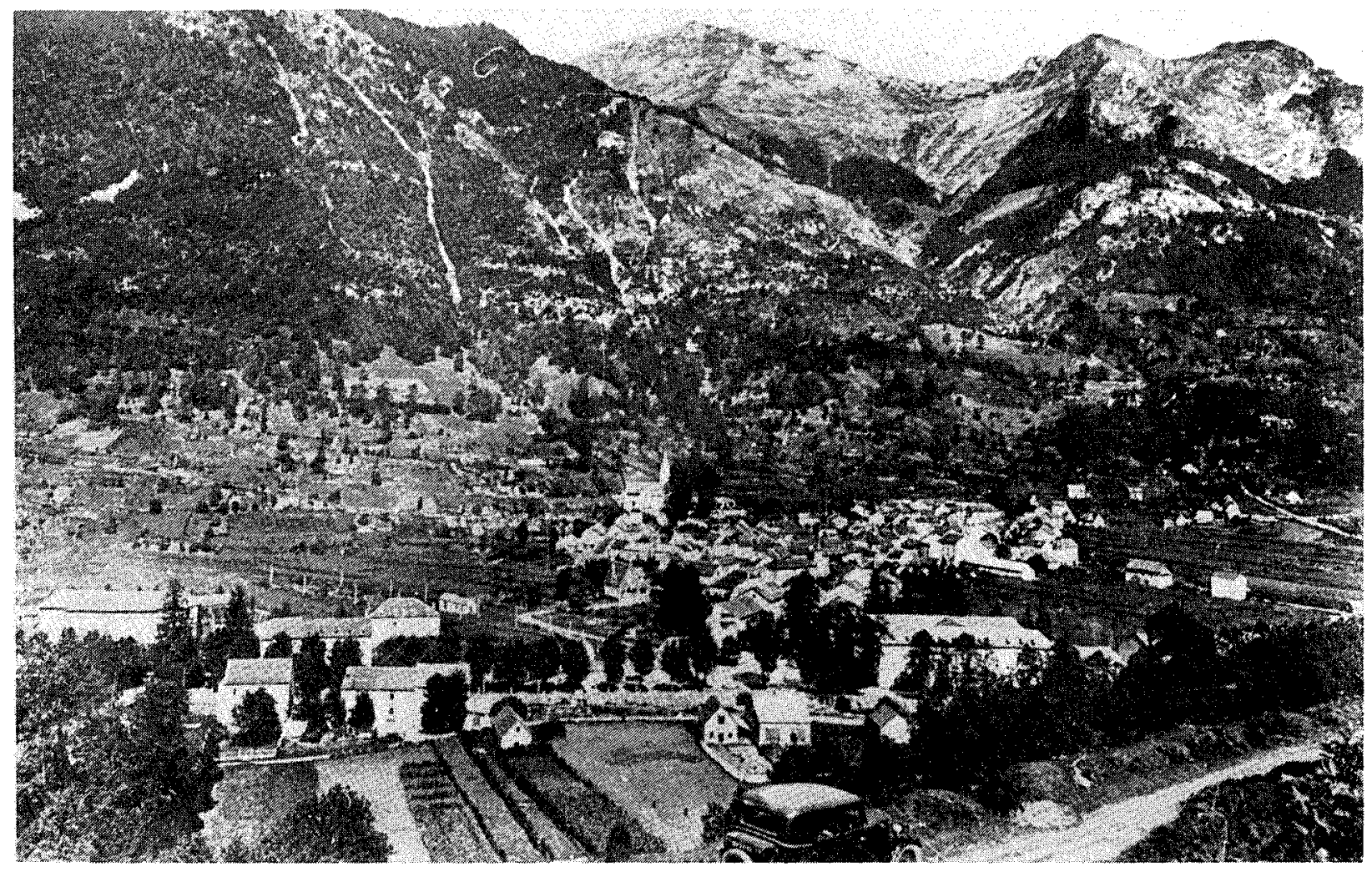

Foto 1. Solana de Aulus hacia 1930: la baja solana aparece cultivada y la solana media presenta abarrancamientos fruto de la deforestación.

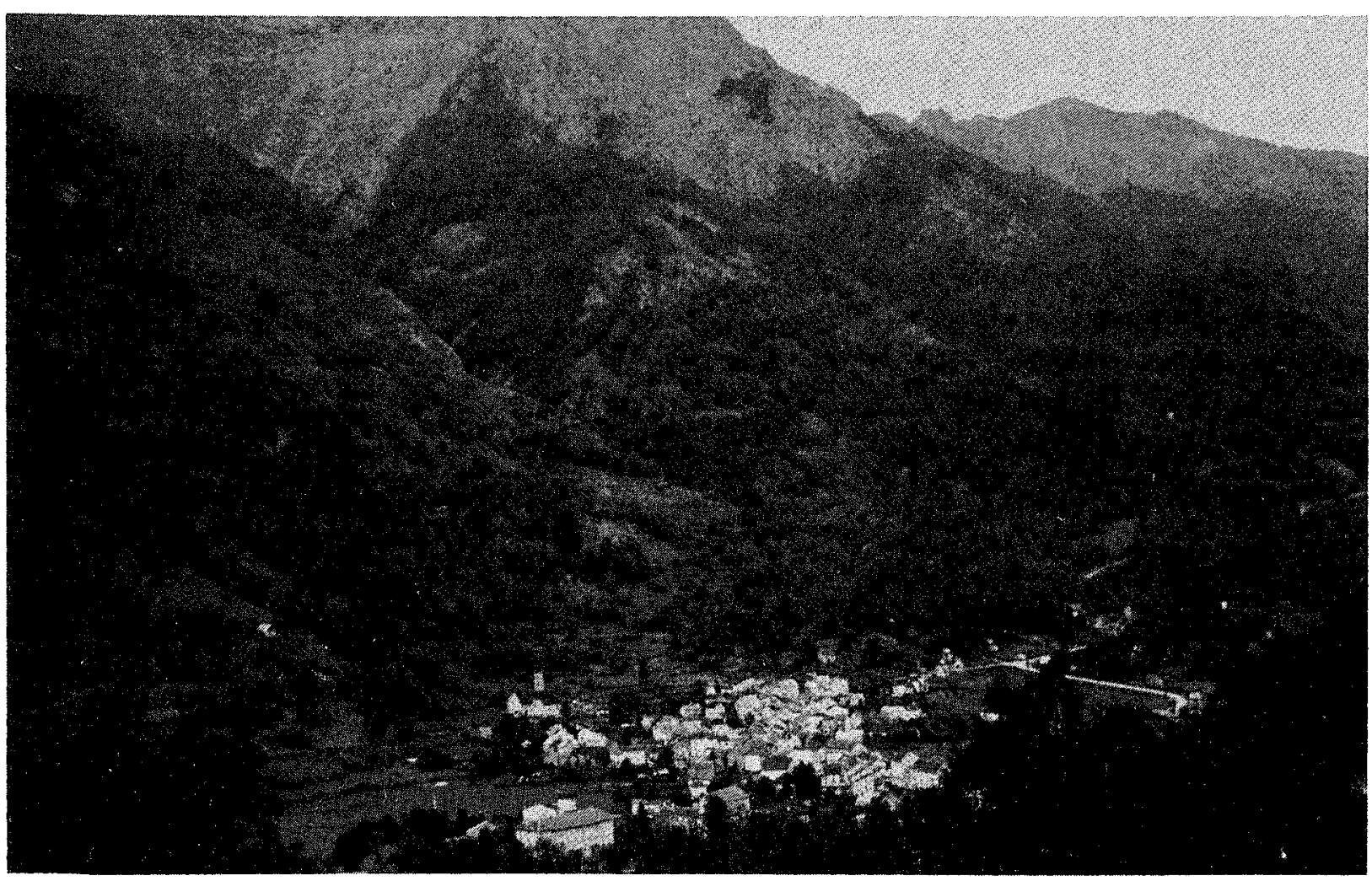

Foto 2. En las solanas baja y media se constata una importante recolonización vegetal. 
